\title{
LA ADAPTACIÓN MORFOLÓGICA DEL VERBO CULTO
}

JAVIER ELVIRA

Universidad Autonoma de Madrid

\section{Preliminar}

La investigación de los procesos de adaptación morfológica del léxico culto presenta un doble interés para la historia de la lengua española y para la teoría morfológica en general. Interesa a la primera en la medida en que el lado morfológico del cultismo es el más desatendido por los abundantes estudios que se han realizado sobre esta cuestión. A la morfología teórica, por otro lado, la observación de estos procesos le proporciona un criterio posible para la elaboración de conceptos como los de estabilidad o productividad ${ }^{1}$.

Parece razonable suponer que que la actividad de recuperación culta de léxico y la de incorporación de préstamos en las lenguas modernas están, ante todo, reguladas y provocadas por las necesidades expresivas experimentadas en el medio cultural en que se producen. Es sabido también que, con independencia de la situación cultural específica, las lenguas se muestran,

1 Una muestra de esta rentabilidad teórica la encontramos en los trabajos de Wolfang U. WURZEL; vid., por ej., «Systemdependent morphological naturalness in inflection», en DRESSLER, Wolfgang U., Willi MAYeRTHALER, Oswald PANAGl y Wolgang U. Wurzel, Leitsmotifs in Natural morphology, SLCS, Amsterdam: Benjamins, 1987, pp. 59-96 (esp. p. 87). 
desde un punto de vista morfológico o sintáctico, mucho menos receptivas e imponen límites a este tipo de innovaciones. Esta diferencia de actitud no ha de extrañar, pues en la morfología y en la sintaxis predomina lo sistemático, lo regulado por principios recurrentes y productivos. Si, con relación al léxico, se ha afirmado que cada palabra tiene su propia historia ${ }^{2}$, de pocos morfemas o estructuras sintácticas podría decirse algo parecido, pues entre ellas predomina la interdependencia, el modelo imitable y, en general, la historia compartida.

La consideración del cultismo como un préstamo, con las salvedades a que esta equiparación habría de llevarnos, nos permite confirmar en otro terreno las anteriores observaciones pues, en efecto, la influencia por vía culta de la morfología o la sintaxis latinas en la lengua española ha sido relativamente muy inferior a la que el latinismo léxico ha ejercido en nuestro vocabulario ${ }^{3}$. Pero la facilidad relativa con que el léxico culto o prestado se ha incorporado a la lengua española no ha de interpretarse como absoluta disponibilidad de ésta a recibirlo.

La mayoría de los préstamos y cultismos de nuestra lengua son sustantivos, adjetivos y verbos. En muy pocos casos, pertenecen a otras categorías gramaticales. El verbo, entre las tres mencionadas, presenta en español una morfología muy complicada que no coincide con la mofología del verbo latino, aunque remita genéticamente a ella. Esto significa que reincorporar un verbo latino al uso español supone contraponer esquemas morfológicos que no han de ser necesariamente coincidentes. En otras palabras, los verbos latinos son recuperables pero no su flexión. Se hace necesario, por tanto, adaptarlos a la morfología española. La cuestión que se plantea entonces es la relativa a los procedimientos y criterios por medio de los cuales se lleva a cabo esta acomodación. Intentaré en lo que sigue aproximar una respuesta a esta pregunta. Con tal motivo, propongo el examen de algunos aspectos del proceso de acomodación de un grupo de verbos cultos de la lengua española, pertenecientes a las conjugaciones segunda y tercera ${ }^{4}$ y reincorporados al español a partir del siglo $\mathrm{XV}$.

2 La frase en cuestión se atribuye a Jules GILLIERON («Chaque mot a son histoire»); Yakov MALKIEL la incorpora como título de uno de sus trabajos, en el que muestra hasta qué punto es posible encontrar relaciones de dependencia en el léxico. Cf.: «Each word has a history of his own», Glossa, I, 1967, pp. 137-149.

3 Vid. Manuel Alvar y Sebastián Mariner, «Latinismos», Encliclopedia Lingüística Hispá. nica, vol. Il, Madrid: CSIC, 1967, p. 17; José Jesús DE Bustos TovAR, Contribución al estudio del cultismo léxico medieval, Madrid, 1974.

4 El corpus ha quedado delimitado en su aspecto cuantitativo con la ayuda de un diccionario inverso del español (he utilizado el de Ignacio BosQUE y Manuel PéreZ FERnÁndez, Diccionario inverso de la lengua española, Madrid: Gredos, 1987, que reordena las voces contenidas 


\section{El CRITERIO DE IMITACIÓN. LOS NUEVOS MORFEMAS TEMÁTICOS}

La actividad recuperadora de verbos por vía culta hubo de resolver, ante todo, dos opciones. La primera se refería a la eventual modificación del timbre vocálico del radical del verbo. La segunda decisión era relativa a la adscripción del verbo a una u otra conjugación. Por lo que se refiere al primer problema, los datos muestran que los eruditos del siglo XV y siguientes tienden a imitar, en la medida de lo posible, el vocalismo radical del étimo latino, con independencia, naturalmente, de la cantidad de la vocal correspondiente. Con este criterio, que persigue mantener la relación etimológica de la palabra, los verbos que, por ejemplo, tenían $e$ larga o breve en su radical latino, prefirieron, en principio, mantener en español la misma vocal radical. Ejemplos de ello son los cultismos correspondientes a los latinos discernere, sugerere, competere, surgere, sumere o discurrere.

Ahora bien, esta imitación culta del vocalismo radical latino encuentra de vez en cuando algunas limitaciones que se derivan de las peculiaridades de la fonología del castellano. Es el caso de los cultismos con diptongo latino ae en su étimo, que resulta inimitable como tal diptongo. Valga como ejemplo la adaptación de adhaerère como adherir y praeferre como preferir, que proponen la -e-como vocal palatal sustituta del diptongo.

Pero acaso los problemas de adaptación morfológica más importantes los presentan aquellos verbos con vocal radical $-i$ - $0-u$ - pertenecientes a la segunda o tercera conjugación latinas. En efecto, ¿cómo imitar sin más el vocalismo de verbos como scindere, retinére, recurrere, instruere? $\mathrm{O}$ bien, planteado en otros términos, ¿por qué nos suenan mal los infinitivos hipotéticos *escinder, *retiner, *recurrer, instruer? La respuesta a esta pregunta tiene que ver con el hecho de que la vocal - $i$ - está excluida del vocalismo radical de la segunda conjugación castellana.

Debemos recordar que, tanto en latín como en español, el cromatismo vocálico del verbo puede tener carácter distintivo y permitir la identificación de la clase morfológica, esto es, de la conjugación a la que el verbo pertenece. Esta es la función que en latín desempeñaba la llamada vocal temática, que se

en la edición de 1984 del diccionario académico y en la de 1980 del etimológico de Joan Corominas y José Antonio Pascual), lo que ha permitido obtener un listado de verbos de las conjugaciones segunda y tercera. Con los datos filológicos contenidos en el mencionado Diccionario Crítico Etimológico Castellano e Hispánico de Joan Corominas y José A. Pascual (Madrid: Gredos, 1." ed., la reimp. 1989) hemos seleccionado los verbos reincorporados al español a partir del siglo XV. 
insertaba entre el radical y las desinencias verbales. La evolución castellana se orienta, por el contrario, hacia un debilitamiento parcial de la función identificadora de la antigua vocal temática latina y la absorción de esta función temática por la vocal radical.

En la gramática latina, la identificación de la vocal temática surgió en el terreno de la descripción y enseñanza de la lengua por parte de los propios autores latinos, quienes intentaron poner orden en la considerable variedad formal del verbo latino. Dos milenios después, la lingüística latina sigue ocupada en la tarea de analizar los elementos que integran las formas verbales. Estos estudios contemporáneos continúan en muchos casos aislando una vocal temática (incluso en la descripción del sustantivo), pero la extensión y el sentido de esta unidad difiere según los planteamientos de cada autor ${ }^{5}$. Por otro lado, las unidades identificadas como temáticas en latín no coinciden necesariamente con las aisladas en las formas transmitidas, ni siquiera en los casos de conservación total de la forma originaria: amo, que vale tanto para el español como para el latín, lleva vocal temática en esta lengua (am-o), según algunos gramáticos ${ }^{6}$, pero es analizado como forma atemática (vgr.: /am- $\emptyset-0-\emptyset /)$ por algunas descripciones del español?

Por su parte, la gramática histórica de orientación románica se atuvo desde sus orígenes a una visión de la morfología en la que la consideración segmental de la palabra era vista con toda precaución y fuera, desde luego, de pretensiones estructurales. En su obra más conocida, Meyer-Lübke distribuye el capítulo dedicado a la flexión verbal en dos apartados claramente diferenciados, dedicados, respectivamente, al radical verbal y a las desinencias, sin que se encuentre mención directa o indirecta a la existencia de morfema temático alguno ${ }^{8}$. Es cierto que Meyer-Lübke utiliza en alguna ocasión la noción de vocal temática, pero la aplica para referirse a la vocal del radical, o tema, y esta vocal no siempre se sitúa en posición intermedia entre el radical y las de-

5 Compárese, por ejemplo, la segmentación del verbo latino, efectuada con criterios historicistas por A. Ernout (Morphologie historique du latin, París: Klincsieck, 195333. pp. 171-172) con la descripción estructural de J. Molina Yévenes (Estudios latinos, I, Barcelona, 1966 -s. v. cap XII: «El verbow).

6 Es el caso de los citados en la nota anterior.

7 Puede encontrarse un análisis crítico de las diferentes posturas segmentales en la morfología del español en el trabajo de Santiago ALCOBA «El morfema temático del verbo español», en Gerd Wotiak y Alexandre Vega (eds.), La descripción del verbo español, Santiago de Compostela: Anexo 32 de Verba, 1990, pp. 9-22.

8 Grammaire des Langues Romanes, Parfs, 1890-1906, vol. II, pp. 177-313 (cito por la reimpresión de Slaktine y Laffitte, Ginebra-Marsella, 1977). 
sinencias $^{9}$. Igual ocurre con los trabajos gramaticales de Menéndez Pidal, para quién el adjetivo temático hace referencia a la vocal del tema o radical y no a sus elementos flexionales ${ }^{10}$.

Esta discrepancia terminológica entre los gramáticos latinos y los que se ocupan de la descripción de las lenguas románicas respecto al lugar donde ha de encontrarse la vocal o morfema temático de un verbo, esto es, el elemento que indica la clase morfológica a la que el verbo en cuestión pertenece, tiene sin duda que ver con el protagonismo adquirido por la vocal del radical del verbo románico en la marca de la clase de conjugación. Th. Montgomery ha mostrado, en un articulo muy conocido ${ }^{11}$, que el timbre de la vocal del radical ha jugado un papel fundamental en la redistribución de las verbos latinos desde las antiguas conjugaciones latinas hasta los nuevos modelos flexivos españoles. Según el mencionado autor, los verbos con vocales radicales muy cerradas, como es el caso de los que tenían $i$ y $u$, se destinaron a la tercera conjugación castellana. Es lo que ocurrió con verbos como lucēre o ridere, cuyo vocalismo radical favoreció su adscripción a la conjugación -ir. Esta principio de complementaridad, como lo llamó el propio Montgomery, presenta, naturalmente, una casuística más complicada y tiene su manifestación en la exclusión de la - $i$ - y de la - $u$ - del vocalismo radical de la segunda conjugación castellana.

En virtud, por tanto, del hecho evolutivo que se acaba de presentar, los verbos latinos con esquemas vocálicos $i$-ere y $u$-ere resultan esencialmente inimitables y requieren una modificación ya del radical, ya de la desinencia de infinitivo (antigua vocal temática latina). La opción se ha resuelto, en la mayoría de los casos, en el sentido de conservar el vocalismo radical clásico, incorporando el verbo a la tercera conjugación castellana. Es lo ocurrido con los cultismos correspondientes a scindere, residere, seducere o inclüdere, que han mantenido con toda transparencia su vinculación etimológica con el latín.

En otros casos diferentes del esquema i-ere, u-ere, el respeto a la forma radical latina se ha manifestado, si cabe, con mayor firmeza, No habiendo dificultades para admitir, por ejemplo, el esquema e-ere, los verbos de esta forma se han incorporado sin modificaciones: cèdere $>$ ceder, splendere $>$ esplender, repellere $>$ repeler, etc.

9 Así, el párr. n. 597 de la obra de W. MEYER-LÜBKE citada anteriormente, va dedicado al cierre de la vocal temática por efecto de la composición y se refiere a modificaciones del tipo lat. $f a$ cere $>$ reficere, claudere $>$ excludere.

10 Manual de gramática histórica española, Madrid: Espasa-Calpe ${ }^{15}, 1977$. Con tal denominación hace referencia, por ejemplo, a la e larga de metis (p. 295).

11 «Complementarity of stem-vowels in the Spanish second and third conjugations», Romance Philology, XIX, 1976, pp. 281-296. 


\subsection{El modelo de conjugación}

Una vez resueltas las opciones relativas al timbre radical, los autores cultos tuvieron que enfrentarse con el problema de la adscripción del verbo a alguno de los modelos de conjugación existentes en castellano. En este punto, el procedimiento de la simple imitación de la etimología latina se vio restringido por varias limitaciones de Indole morfológica. Es el caso de los verbos que proceden de la 3." conjugación latina, con vocal temática breve y, por consiguiente, acentuación fuerte en el infinitivo, que hubieron de homologar su acentuación al tipo regularmente débil del infinitivo castellano. Pensemos en los verbos cedere o impellere, cuyos correspondientes españoles han desplazado el acento a lo que hoy es la desinencia de infinitivo.

Pero, probablemente, el factor que más claramente ha interferido con el deseo de reproducir la forma latina del verbo haya sido el poder de absorción de la tercera conjugación castellana en -ir.

Téngase en cuenta que la conjugación castellana en -ir no se limita a incorporar los verbos patrimoniales procedentes de la cuarta latina en -ire, sino que ha sido además el destino de buen número de verbos de las antiguas conjugaciones segunda y tercera. La interpretación más extendida de este intenso desplazamiento suele hacer referencia a la abundancia en las mencionadas conjugaciones de verbos cuya primera persona del presente de indicativo tenían la desinencia -eóo o -iō, así como los finales -eam, -iam en el presente de subjuntivo. Para estos finales se debió de practicar una pronunciación popular con yod similar a la misma pronunciación relajada de las correspondientes desinencias de la cuarta conjugación. Esta circunstancia fonética estaría en la base del desplazamiento de verbos como compleo-complère, ferveó-fervére $o$ pariō-parere a la conjugación en $-i r^{12}$.

A la preferencia histórica del verbo español por la tercera conjugación en -ir sobre la conjugación en -er ha debido de contribuir también el hecho de que la distinción morfológica entre ambas conjugaciones no es tan nítida como cabría esperar. Si nos fijamos, notaremos que, en realidad, son muchas más las desinencias comunes a ambos modelos flexivos que las que son pecu-

12 Pero no es seguro que esta yod desinencial haya sido el único o el más importante motivador de este caudaloso desplazamiento de verbos a la conjugación en -ir, porque no son pocos los verbos latinos que, sin tener esta yod en su desinencia de presente, se desviaron igualmente a la tercera conjugación española. Me refiero a verbos como reddó-reddere > rendir, conbattuó - conbattuere >combatir, etc. Puede encontrarse una discusión reciente del tema en el libro de Ralph Penny A History of the Spanish Language, Cambridge: Camb. University Press, 1991, p. 149. 
liares a cada uno de ellos. Ambas conjugaciones difieren solamente en las personas primera y segunda del plural del presente de indicativo (bebemos frente a sentimos), en el imperativo (bebed frente a sentid) y en el futuro y condicional (beberé, bebería frente a sentiré, sentiría). De nada valió la tentativa medieval de extender una desinencia de participio en -udo, peculiar de la segunda conjugación (bebudo, tenudo), porque no consiguió finalmente eliminar de ésta la terminación -ido, extendida desde la conjugación en -ir. No cabe duda, pues, de que esta comunidad de desinencias ha favorecido el trasvase de verbos desde una conjugación a otra. Esta suposición resulta mucho más verosímil a la vista de la presencia casi recurrente de la i en las desinencias que son comunes a ambas conjugaciones (obsérvese que se encuentra, en efecto, en casi todas: bebia-sentía, bebiste-sentiste, bebido-sentido, etc. ${ }^{13}$ ). En realidad, puede decirse que la tercera conjugación en -ir es un modelo relativamente mejor caracterizado que la segunda conjugación, dado que la $i$ se encuentra en todas las formas verbales de su paradigma, ya sea en la desinencia, ya sea en el radical, y ello confiere a esta vocal un papel caracterizador ${ }^{14}$.

Nos explicamos así que desde antiguo se conozca el desplazamiento de verbos castellanos de la segunda a la tercera conjugación en -ir, más absorbente (vgr.; bater > batir, herver > hervir, nozer > nuzir, etc) y, en general, las dudas que la lengua antigua manifiesta continuamente en este capítulo de la morfología verbal 15 .

Esta vacilación se vio favorecida, además, por la situación geográfica del primitivo castellano, situado entre dos zonas iberorromances que se comportaban distintamente en relación con el fenómeno que comentamos. Por un lado, el portugués, con una segunda conjugación mejor caracterizada que la española, mantuvo en la segunda conjugación en -er a muchos verbos cuyos corres-

13 Cf.: Knud Togeby, «L'apophonie des verbes espagnols et portugais», Romance Philology, XXVI, 1973, pp. 256-264 (esp. p. 260). Resulta muy útil la revisión teórica y empírica de la cuestión propuesta por Jesús MARTfNEz SANTOYo en su obra La conjugación castellana en -ir. Origen y formación. Sus alternancias vocálicas, Madrid: Ediciones de la Universidad Autónoma de Madrid, 1988 (ed. en microficha).

14 El papel de la $i$ en la gramática histórica del español ha sido detenidamente evaluado en el sugerente artículo de Yakov MALKIEL «In search of coefficients in diachronic morphological analysis. /i/ as an increasingly dominant vowel in Spanish inflectional morphemes", Proceedings of the Eighth Annual Meeting of the Berkeley Linguistic Society, Berkeley, 1982, pp. 36-78.

15 Casi todos los verbos que seguían los esquemas $i$-ir o-ir en español antiguo conocieron los alternantes $e$-ir, $o$-ir en proporción variable. Valgan como muestra los datos proporcionados por Hildegard Schede en su obra Die Morphologie des Verbes im Altspanischen, Frankfurt: Lang, 1978, cap. 5. 
pondientes castellanos fueron desplazados a la tercera (vgr.: aduzer, encher, morrer, sofrer, etc) ${ }^{16}$. En la zona oriental, por el contrario, fue más acentuada que en el castellano la preferencia por la conjugación tercera, según muestra la adscripción de verbos como escondir, atrevir, exercir, obtenir, possedir, etc. ${ }^{17}$

Igual que en el terreno del verbo patrimonial, la 3." conjugación castellana en -ir ha sido el destino favorito de los cultismos del español pertenecientes al grupo que estudiamos. A ella se han incorporado verbos cultos que tenían las siguientes procedencias:

a) Hay que citar, en primer lugar, y este no es el grupo más numeroso, a pesar de lo que pudiera pensarse, los verbos que pertenecían a la cuarta conjugación latina. Ejs.: disentir $(1600$, dissentire) y otros verbos de la correspondiente familia léxica, así como prevenir (Nebrija, praevenire) y sus parientes léxicos. No cabe duda de que en la adscripción morfologica de estos verbos ha debido de jugar también un papel importante la existencia de precedentes patrimoniales como sentir o venir, como señalaremos más adelante.

b) Algunos deponentes, por su forma, orientaron su ubicación en esta misma conjugación: agreddi, transgreddi.

c) Se incorporan, además, aquellos verbos que tenían en latín una -i- o una - $u$ - en el radical, ya fueran de la 2." (prohibère, dissidère, urgère), ya de la 3." (elidere, incidere, atribuere, fluere). Este tipo de verbos, con esta esquema vocálico $i$-ere, $u$-ere, fueron orientados a la tercera conjugación por el empuje de tres tendencias que ya conocemos. El deseo de imitación del timbre clásico, por un lado, y el empuje de la tercera conjugación castellana, por otro. De manera igualmente decisiva debió de influir, en tercer lugar, el rechazo de la conjugación -er por el vocalismo radical con $-i-0-u-$. Con la conjunción de estos principios se fue configurando en español una nómina muy amplia de verbos cultos de la tercera conjugación y vocalismo radical cerrado a la que pertenecen, entre otros, decidir y su familia, remitir, permitir, seducir y otros del mismo grupo, inhibir o cohibir, existir o resistir, concurrir o recurrir y un largo etcétera.

16 Sobre esta cuestión resulta muy útil el conocido trabajo de Dana A. NELSON «The domain of Old Spanish -er and -ir verbs. A clue to the provenience of the Alexandren, Romance Philology, XXVI, 1972-73, pp. 265-307, esp. p. 280.

17 Cf. Paul M. LLoYd, From Latin to Spanish Vol I: Historical Phology and Morphology of the Spanish Language, Filadelfia: Memoirs of the American Philosophical Society, 1987, p. 287. 


\subsection{Vacilaciones}

A pesar de que, como se acaba de ver, la vitalidad de la conjugación en -ir es un hecho irrefutable, no hay que caer en el error de considerarla el único destino posible del cultismo castellano, dado que la conjugación en -er se vio enriquecida también con no pocos elementos cultos. La causa que determinó la adscripción de determinados verbos eruditos a esta segunda conjugación castellana podría muy bien estar relacionada con el mismo principio de imitación que ya hemos mencionado, puesto que todos ellos comparten la característica de contener la vocal $e$ larga o breve tanto en el radical como en el morfema temático. Valgan como ejemplos accendere > acender, prōcēdere > proceder.

La aplicación sistemática de este sencillo principio de imitación del vocalismo clásico nos habría proporcionado una casuística muy fácil de clasificar si no se hubiera visto interferida por el enorme poder de absorción de la conjugación tercera. Parece, en efecto, que los eruditos castellanos dudaron en más de una ocasión ante la opción de dar al verbo culto una forma más próxima al latín o, por el contrario, de acomodarlo al esquema flexivo más extendido en su lengua. Por esta razón, no son pocos los verbos cultos de este grupo que han presentado vacilaciones. Es el caso, por ejemplo, del verbo emerger (lat. emergere), que conoció la variante emergir, igual que nuestro moderno sumergir (lat. submergere) se usó en la forma latinizante sumerger. Todavía hoy la Academia mantiene la convivencia de converger (lat. convergere) con convergir, más acorde con la moderna morfología. Nuestro verbo discernir (lat. discernere) se incorporó al español en el segundo cuarto del siglo XV, pero lo hizo en la forma discerner, que utilizaron autores como Mena y Santillana. Curiosamente, el verbo discernir es hoy irregular, porque no permite la inflexión por yod desinencial que experimentan todos los verbos de la conjugación tercera, y dice discerniendo y no *discirniendo, discernió y no *discirnio. Esta misma peculiaridad presentan los citados sumergir y convergir, que se conjugan como emerger. El caso, por fin, del doblete competer, competir, ambos del lat. competere, nos verifica la posibilidad de que la vacilación se traduzca en especialización semántica que da lugar a dos unidades léxicas diferentes.

La doble ubicación de estos verbos cultos, aun siendo frecuente, no fue general. En muchos casos se vio frenada, probablemente, por el influjo de algún precedente de cromatismo vocálico similar. Si un verbo como pretender (lat. praetendere) vaciló poco o nunca, ello se debe, quizás, a que en la lengua 
se conocían y se usaban desde antiguo verbos tan frecuentes como tender, prender y sus derivados.

Por esta misma razón, esto es, porque el vocabulario castellano no tenía un verbo con estructura formal similar que orientase desde un principio la ubicación de los latinismos, los cultimos correspondientes a compellere, expellere, impellere o repellere han conocido soluciones variadas. Mientras la Academia reconoce todavía el doblete compeler - compelir, admite la conjugación de los otros cultismos según el modelo de la segunda, esto es, expeler, impeler o repeler.

La presión del modelo precedente se puede hacer sentir hasta el punto de provocar la adscripción morfológica del verbo según principios diferentes de los señalados hasta ahora. Según estos principios, verbos como abstinére y obtinére deberian de haberse recuperado como *abstinir $y{ }^{*}$ obtinir, respectivamente; pero la presión de un verbo tan usado como tener resolvió sin vacilación la ubicación de estos verbos en la segunda conjugación. La influencia morfológica de tener sobre los verbos de esta serie parece confirmarse con la constatación de que sus perfectos simples obtuvo, contuvo, retuvo se formaron sobre el modelo establecido por tener.

\section{SUBMODELOS FLEXIVOS}

Las decisiones que hubieron de tomar los introductores de verbos cultos en nuestra lengua no acaban, sin embargo, con la elección de conjugación. Una vez acomodado cada verbo en el tipo correspondiente, se hacía necesario optar por alguna de las posibilidades flexivas que cada conjugación conoce. Las conjugaciones castellanas no eran ni son modelos uniformes de flexión sino que presentan, como es bien sabido, alternancias de tipo y origen muy variados. Por lo que se refiere a los verbos que nos ocupan y ciñendonos a los paradigmas de presente de indicativo, el español medieval presentaba una situación que podemos resumir en los siguientes términos.

La segunda conjugación castellana en -er presentaba en el tema de presente un cuadro flexivo similar al actual, salvadas las oportunas diferencias de frecuencia o número de los que la siguen. Por un lado, había un núcleo de verbos, como beber, o coger, que se conjugaba en el presente sin ningún tipo de variación alomórfica; otros verbos, por el contrario, habian conservado o incorporado analógicamente la alternancia con diptongo ie/e, ue/o, para formas 
formas fuertes y débiles, respectivamente. Se conjugaban así verbos como querer o volver.

La tercera conjugación presentaba, por su parte, una situación que difiere parcialmente de la moderna. Se usaba también aquí el presente con diptongo alternante, seguido por verbos como mentir o morir. Por otra parte, existía ya la flexión que podemos llamar alternante, en la que la vocal radical -e-/-o- experimentaba, como hoy, una alternancia en $-i-/ /-u$ - en las formas fuertes. Se conjugaban de esta forma verbos como medir o cobrir. Con menor frecuencia, según señala $\mathbf{R}$. Menéndez Pidal ${ }^{18}$, algunos verbos se conjugaban de acuerdo con un esquema sin ningún tipo de variación de la vocal radical $-i-/-u-$. De esta forma se conjugaban a veces verbos como escribir, vivir o sufrir, que se podían formar también según el esquema metafónico más habitual.

Todas las alternancias morfologicas a que hemos aludido tienen su originaria razón de ser en procesos fonéticos que, como la diptongación, culminaron bastantes siglos antes. Deberíamos esperar, por tanto, que tales modificaciones formales habrían de estar ausentes del radical de los verbos cultos. Por otra parte, la incorporación de esta variación en el radical contribuye a aumentar la irregularidad morfológica, al menos en el sentido de que alternancias como sentir - siento no parecen aportar ninguna información adicional sobre el significado o función del verbo. Cabría esperar, por ello, que la reintroducción culta precindiría de tales alternancias no significativas y nos proporcionaría verbos «limpios» de esta clase de anomalías. No son pocos, sin embargo, los verbos que. aun habiendo sido rescatados en fecha relativamente tardía por la labor erudita, se han conjugado desde el principio y sin vacilación con algún tipo de alternancia alomórfica, lo que confirma indirectamente que tales variaciones no son tan indeseables como cabría suponer.

Nos preguntamos entonces qué criterio explícito o implícito decidió la incorporación de unas u otras alternancias. Para intentar una respuesta a esta pregunta propongo echar un vistazo, en primer lugar, a los verbos cultos que han incorporado la flexión diptongante. Uno de los casos más significativos es probablemente el de la serie abstener (lat. abstinère), obtener (lat. obtinére) y otros del mismo grupo, incluso anteriores al siglo XV. Lo curioso de estos verbos es que, a pesar de tener una - $i$ - en el radical latino, han desarrollado una diptongación que contradice su propia etimología. La suposición de que la presión de tener ha influido en la incorporación del diptongo no parece descabellada, sobre todo cuando se constata, como ya hemos hecho anteriormente, el influjo de tener en la formación del perfecto de estos verbos (abstuvo, obtuvo, etc).

18 Op. cit., n. ${ }^{\circ} 105$, p. 272. 
Probablemente, los casos que se discuten en el presente contexto tienen que ver con la misma tendencia a conformar la morfología de unos verbos recién llegados a la lengua con arreglo al precedente establecido por otros verbos de antigüedad y arraigo suficientes. Sin duda, unos casos podrán analizarse con mayor claridad que otros. No resulta difícil aceptar que los cultismos presentir (lat. praesentīe), disentir (lat. dissentïe), o asentir (lat. assentïre) se sintieron compuestos del patrimonial y antiguo sentir, lo mismo que los cultos provenir (lat. provenire), prevenir (lat. praevenire), intervenir (lat. intervenire), etc, sugieren una relación derivativa con venir, e incorporaron unos y otros sin vacilación el diptongo en su flexión.

En otras ocasiones, aunque la relación derivativa o semántica no sea tan nítida, no hay que excluir que el parecido puramente formal con otro verbo sugiera por sí mismo un «aire de familia» que decida la flexión del verbo. Los cultismos de la serie inferir, proferir, etc, en su mayoría del siglo $\mathrm{XV}$, pudieron haberse sentido como compuestos prefiiales del verbo ferir, de antiguo abolengo en español. Lo más curioso del caso es, por otra parte, que el parentesco formal de este grupo de verbos con ferir es castellano y no latino, puesto que en su origen estos verbos eran derivados de ferre (inferre, praeferre, proferre) $y$ no de ferire.

También han diptongado de forma decisiva los cultismos de la serie advertir (lat. advertere), pervertir (lat. pervertere), invertir (lat. invertere) o divertir (lat. divertere), algunos de los cuales se conocen con la terminación -er (vgr. subverter en el siglo XV o ya reverter en el XIII). En todos ellos podemos reconocer el modelo diptongante del patrimonial verter, que también ha mostrado una vacilación popular respecto a la conjugación en la que se ubica.

Igualmente claro parece ser el precedente para la flexión con diptongo de los verbos del tipo adquirir ${ }^{19}$ (S. XV; lat. adquirere), inquirir (s. XV; lat. inquirere) o del también culto, aunque más antiguo, conquerir (lat. conquirere), que se usó hasta el siglo XVII ${ }^{20}$. En unos y otros, como ha señalado Malkiel, debemos ver el efecto del modelo establecido por el patrimonial querer, influjo que la semántica ha podido reforzar en algún caso ${ }^{21}$.

19 En la lengua antigua era más corriente adquerir; vid. Rufino José CuERVo, Diccionario de contrucción y régimen de la lengua castellana, vol. I, Bogota: Instituto Caro y Cuervo, 1886 (utilizo reimpresión de 1953, pp. 214-216).

20 CUERvo, op. cit., vol. I, pp. 400-401.

21 Véase el trabajo de Yakov MALKIEL «Rising diphthongs in the paradigms of Spanish learned -ir verbs», Hispanic Review, LII, 1984, pp. 303-333. 
Pero, como ya hemos señalado, no es el diptongante el único tipo alternante en español antiguo o moderno. Muchos verbos cultos prefirieron acomodarse al modelo rival del anterior, que hemos dado en llamar alternante. Tampoco es difícil encontrar afinidades formales que pudieron haber orientado esta acomodación morfológica. Desde antiguo son conocidos en español los verbos patrimoniales pedir (lat. petere) y despedir (lat. expetere) que siguen este modelo. A partir del siglo XV empezaron a usarse los cultos impedir (lat. impedire) y expedir (lat. expedire), que debieron de sentirse emparentados léxicamente con los anteriores (en contra de la realidad etimológica) y acomodaron a ellos su flexión. Mucho más justificada, en términos etimológicos, está la relación léxica del cultismo investir (lat. investire) con el patrimonial vestir y ello explica su conjugación de presente.

La existencia de modelos flexivos que atraen a su modelo a los verbos cultos recién incorporados puede confirmarse por vía negativa o indirecta a la vista de ciertos casos particulares en los que justamente la ausencia de un modelo que determine decididamente la flexión introduce dificultades en la adaptación morfológica de algunos verbos. Me refiero a casos como los de convergir / converger y su pariente divergir, ambos del siglo XIX, este último sin doblete académicamente reconocido; cabe también en este grupo el verbo sumergir, del siglo XVII. Son estos los tres únicos casos de la conjugación tercera con vocal radical - $e$ - que no se acomodan ni al modelo diptongante ni al llamado metafónico, pese a lo cual M. Seco, en su conocido Diccionario de dudas... afirma que divergir «Es verbo regular: su pretérito es divergió (no divirgió) $\star^{22}$. Claro está que el conocido académico entiende la irregularidad en el sentido de ausencia de alomorfia: convergir o divergir no alteran su raíz en ningún lugar de su paradigma. Pero esta inmovilidad del radical es, en sí misma, una irregularidad para los verbos en -ir de tema en -e-, que presentan siempre una de las dos alteraciones. El origen de la dificultad de adaptación de estos verbos consiste quizá en que la secuencia -ergir era insólita en el uso general del verbo español en el momento en que se produjo la entrada de estos verbos; esta ausencia de precedentes debió de contribuir a rechazar por anómalas o extrañas las formas alomórficas que implicaban modificación del radical.

Otro resultado diferente de la misma o parecida situación es el que presentan los cultismos agredir y transgredir, que el citado $\mathrm{M}$. Seco considera defectivos. Ambos verbos se conjugan, según Seco, «en las formas que tienen

22 Manuel SECo, Diccionario de dudas y dificultades de la lengua española, 9." ed. renovada, Madrid: Espasa-Calpe, 1986, p. 152. 
en su desinencia la vocal $i \aleph^{23}$, si bien el citado autor admite que la forma agrede no es desconocida. Nótese que las formas con $i$ en la desinencia, a las que se hace alusión, son precisamente las formas débiles del paradigma, esto es, aquellas que son comunes a los dos submodelos de conjugación teóricamente posibles; la conjugación defectiva de estos verbos evita, por tanto, la variación alomórfica y el posible rechazo, por inhabituales, de las formas fuertes.

\section{La ReVITAlización de La FleXión No Alternante}

Según se ha señalado anteriormente, existió en la tercera conjugación del español antiguo una flexión no alternante con $-i-/-u$ - temáticas (submodelos $i$-ir, $u$-ir). Los casos más conocidos y citados, escrivir, vivir, cubrir o cumplir solían acomodarse también a la flexión del modelo llamado alternante (escrevir, bevir, cobrir o complir, respectivamente).

La competencia entre las dos soluciones flexivas dista de haberse resuelto después de la Edad Media, como se deduce de la mención expresa que hace Valdés a la perduración de la misma en la fecha de composición de su Diálogo de la lengua (1535). El pasaje en cuestión no se ocupa, ciertamente, de la alternancia escrevir / escrivir como problema morfológico, sino como cuestión fonética. Lo contempla, dicho en términos actuales, como un problema de vacilación del vocalismo átono, ya que se refiere también a casos de vacilación en sustantivos. Pero ello no quita valor, especialmente cronológico, al testimonio de Valdés. El pasaje en cuestión es el siguiente:

MARCIO: En algunos vocablos avemos mirado que muchos de vosotros ponéis i donde otros ponen $e$.

VALDES: Dezid algunos.

MARCIO: Vanedad o vanidad, envernar o invernar, escrevir o escrivir, desfamar o disfamar.

23 Op. cit, pp. 22 y 363 (s. v. AGREDIR y TRANSGREDIR, resp.). S. FERNANDEZ RAMIREZ documenta algunos ejemplos del presente siglo en los que se propone la solución agride e incluso agriede. Vid. Gramática española. 4. El verbo y la oración, Madrid: Arco, 1986, p. 200, n. 10. 
VALDÉS: Si bien avéis mirado en ello, en todos éssos pongo yo siempre i y no e, porque me parece meior; y porque siempre lo he usado assi, y veo que los más primos en el escrivir hazen lo mesmo. Los que hazen el contrario, por ventura es por descuido.

MARCIO: Por descuido no puede ser, porque Librixa en su Vocabulario los escribe con e .

VALDÉS: No me aleguéis otra vez para el castellano el autoridad de Libri$x a$ andaluz, que me haréis perder la paciencia. ${ }^{24}$

Sea como fuere, lo cierto es que la situación de escasez relativa de verbos en $-i$ - / $-u$ - que se acomodan al modelo sin alternancia se modifica notablemente a partir del siglo $\mathrm{XV}$ y posteriores, como consecuencia de la adscripción a este tipo de abundantes verbos cultos que en latín respondían al esquema vocálico $i$-ere, $u$-ere, con independencia de la cantidad de las vocales. Como ya hemos visto, los verbos como scindere o redücere resultan de difícil acomodación a la segunda conjugación castellana debido al rechazo por ésta de las vocales temáticas $-i$ - y - $u$-. Como también se ha apuntado, la solución más normal a esta dificultad fue la de respetar el timbre de la vocal radical e incorporar los verbos a la tercera conjugación, dando como resultado verbos castellanos con esquema vocálico $i$-ir / $u$-ir. Por esta vía de acomodo se ha incorporado al español un nutrido grupo de verbos, entre los que se encuentran admitir (s. XV), asistir (s. XVI), existir (s. XVII), restringir (s. XVI), incidir (s. $X V I$ ), residir (s. XV), escindir (s. XIX), inhibir (s. XVI), excluir (s. XV) conducir (s. XV), atribuir (s. XV) y sus numerosos parientes etimológicos.

El efecto más importante de esta abundante incorporación culta fue, lógicamente, que lo que en la lengua medieval era un tipo de conjugación relativamente marginal se convirtió con el paso del tiempo en un modelo cada día más habitual. No hay que descartar, por tanto, que la sustitución de las antiguas formas medievales escrevir, sofrir, etc, por las que son hoy de uso general se viera favorecida por el avance que la reintroducción culta dio al nuevo modelo.

24 Juan DE VALDÉs, Diálogo de la lengua; ed. de A. Quilis, Barcelona: Plaza \& Janés, 1984, pp. 114-115. 


\section{GRADO DE ADAPTACIÓN Y COMPLEJIDAD MORFOLÓGICA}

Lo visto hasta ahora, si ha sido adecuadamente interpretado, nos permite obtener una visión, aunque sea provisional, de la manera en que se ha producido la incorporación de los verbos cultos a la morfología española. Esta tarea de enriquecimiento lexical del español ha combinado sabiamente diversas tendencias, no siempre concordantes. La actitud de respeto y admiración por la cultura clásica, más intensa en unas épocas que en otras, ha propiciado el deseo de mantener la imagen latina de muchos verbos, siempre que no lo impidieron los complejos mecanismos de estructuración de los paradigmas verbales. Este prurito de imitación tuvo que contenerse ante la fuerza de tendencias morfológicas de antiguo arraigo en español. Se dejó sentir, como hemos visto, el efecto de la tendencia ya secular a favorecer las conjugaciones mejor caracterizadas. No menos importante debió de ser el poder de arrastre de determinados verbos de extendido uso a la hora de decidir entre alternativas de flexión.

Cabe suponer que los eruditos del siglo XV y posteriores no eran siempre capaces de expresar en términos de descripción lingüística por qué incorporaban un verbo a una u otra conjugación o por qué lo conjugaban con diptongo o con vocal metafónica. El sentido de la eufonía, del que todos somos participes, no necesita de teoría lingüística alguna para que surta efecto en nuestro uso cotidiano de la lengua y fue, probablemente, el que permitió que se manifestaran las tendencias morfológicas que hemos mencionado.

El resultado ha sido que el español se ha enriquecido con una nómina muy importante de verbos morfológicamente «a punto», perfectamente integrados, en la mayoría de los casos, en el sistema morfológico del verbo. Cualquiera de estos verbos, por inhabitual o escogido que parezca, podrá conjugarse sin problemas en todos sus tiempos, modos o personas. Los casos de defectividad, debida a algún tipo de indecuación al sistema o a falta de uso, son minoritarios en relación con la más habitual incorporación plena a los modelos flexivos con vitalidad en la lengua.

A la vista de estos hechos surge la tentación de extraer conclusiones más generales sobre la acomodación del cultismo en español. Antes de caer en ella deberíamos examinar lo ocurrido en la reintroducción de otro tipo de palabras, muy en particular la de los sustantivos. La oportunidad de hacerlo con detenimiento habrá que buscarla en otro lugar. Conformémonos, de momento, con un rápido vistazo a episodios bien conocidos de la historia del sustantivo para adelantar la impresión de que los hechos en este terreno se han producido de una manera bien diferente. 
La mofología del sustantivo español resulta, ocioso es decirlo, mucho menos complicada que la del verbo. La flexión del número, es relativamente sencilla. El morfema de plural no es sincrético de ningún otro y se aplica de forma automática a todos los sustantivos o adjetivos, con la incorporación ocasional del alomorfo -es tras final consonántico. No es diferente para el masculino o el femenino. No implica metafonías o cualquier otro tipo de modificaciones fonéticas que provocan alternancia alomórfica del radical y, por consiguiente, excluye la elección entre modelos alternativos. No provoca tampoco desplazamientos acentuales. A esta última circunstancia se debe justamente la dificultad de expresar en plural algunos sustantivos como curriculum, hipérbaton, déficit, etc. Estos sustantivos son esdrújulos y terminados en consonante, lo que resulta insólito en la estructura del léxico patrimonial español y, provoca, por rechazo de la acentuación sobreesdrújula, la aplicación automática del plural regular.

Se deduce de ello que la simplicidad de un sistema morfológico puede conllevar dificultadas de acomodo para determinados elementos de estructura irregular y que, a la inversa, la complejidad formal requiere adaptación y excluye la anomalía en mayor grado. Dado que esta idea parece bastante verosímil, no estaría de más recuperar el interés decimonónico por la noción de naturalización $^{25} y$ desarrollarla y ampliarla con nuestros datos. Serla una forma indirecta de rendir homenaje a algunos gramáticos del siglo pasado, de quienes proceden los trabajos pioneros en el terreno que ahora exploramos.

25 Aparece como «Eingebürgerung» en Hermann Paul, Prinzipien der Sprachaeschichte, 1880, 8. ed., Tubinga: Max Niemeyer Verlag, 1975. Se trata del capitulo 22. ${ }^{\circ}$, sobre «Sprachmischung», que examina especialmente el proceso de adaptación de los préstamos. El apartado final de este capítulo hace referencia al prestamo procedente de etapas anteriores de la historia de la misma lengua que lo recibe. 